\title{
The Results of Recurrent Patellar Dislocation Treatment With MPFL Reconstruction in Adolescents With a Minimum Three-year Follow-up: A Prospective Study
}

\section{Krzysztof Małecki ( $\sim$ krzynormal@wp.pl)}

Polish Mother's Memorial Hospital - Research Institute https://orcid.org/0000-0001-8014-479X

Pawet Flont

Polish Mother's Memorial Hospital-Research Institute: Instytut Centrum Zdrowia Matki Polki w Lodzi Jacek Beczkowski

Polish Mother's Memorial Hospital-Research Institute: Instytut Centrum Zdrowia Matki Polki w Lodzi

\section{Wojciech Stelmach}

Polish Mother's Memorial Hospital-Research Institute: Instytut Centrum Zdrowia Matki Polki w Lodzi

\section{Kryspin Ryszard Niedzielski}

Polish Mother's Memorial Hospital-Research Institute: Instytut Centrum Zdrowia Matki Polki w Lodzi

\section{Research article}

Keywords: recurrent patellar dislocation, adolescents, medial patellofemoral ligament, patellar instability

Posted Date: June 1st, 2021

DOI: https://doi.org/10.21203/rs.3.rs-529098/v1

License: (a) (i) This work is licensed under a Creative Commons Attribution 4.0 International License.

Read Full License 


\section{Abstract}

\section{Purpose}

The aim of this prospective study is to perform a clinical and radiological assessment of the results of surgical treatment in a homogenous group of adolescents with recurrent patellar dislocation (RPD), using medial patellofemoral ligament (MPFL) reconstruction as the basic technique.

\section{Methods}

Twenty-two patients reported to the follow-up examination after at least three years, including four patients who underwent bilateral surgery ( 26 knees). The mean age at the time of the surgery was 15.4 years. The subjects were asked to complete the Lysholm-Tegner Knee Scale and the Kujala Anterior Knee Pain Scale before surgery and after follow-up. Based on the imaging results, the Caton-Deschamps Index (CDI), congruence angle (CA), patellofemoral angle (PFA) and Wiberg classification of the patella shape were assessed.

Results

Two incidents of patellar redislocation was noted. Both the Lysholm-Tegner and Kujala Scale scores significantly improved after follow-up $(p<0.001)$. CDI did not change significantly $(p=0.681)$. The values of both PFA and CA significantly decreased after surgery $(p<0.001)$. An incorrect congruence angle (patellar shift) was present in 22 knees pre-op and ten post-op ( $p=0.002)$. Increased patellofemoral angle (patellar tilt) was present in 21 knees pre-op and seven post-op $(p<0.001)$. A statistically significant correlation was demonstrated between PFA and both Lyscholm-Tegner and Kujala score (in both $p<0.001, r=-0.5$ ). A slight, but significant, correlation was found between CA and Kujala score $(p=0.008, r=-0.036)$.

\section{Conclusion}

Surgical treatment causes a considerable improvement in the functional assessment of patients, as well as anatomical conditions within the patellofemoral joint.

ClinicalTrials.gov record No PMMHRI-BC0.34/2019

ClinicalTrials.gov Identifier: NCT03983213

https://clinicaltrials.gov/ct2/show/NCT03983213

Registered 06/12/2019 - Retrospectively registered

\section{Introduction}

Medial patellofemoral ligament (MPFL) reconstruction has grown in popularity to become the method of choice in treating recurrent patellar dislocation (RPD). However, this growth has been accompanied by an 
increase in the number of novel operating techniques focussing on more targeted techniques that respond to anatomical abnormalities [1-11]. However, it is also important that isolated MPFL can be performed successfully regardless of the anatomical condition [12-14].

Similar discussion concerns the fixation point, i.e. whether it should be anatomically dependent, radiologically dependent or isometrically dependent. It is commonly known that the location of the femoral attachment determines the tension within the whole range of motion and conditions efficient rehabilitation; it also ensures good stability of the patella and prevents pain and early degenerative lesions in the patellofemoral joint [15-19].

The analysis of the treatment should include homogenous groups of patients with regard to their age and sexual maturity. It has been demonstrated that children prior to maturation are more exposed to the risk of redislocation and need to be treated with physeal-sparing methods $[9,20]$.

The aim of this prospective study is to perform a clinical and radiological assessment of the results of surgical treatment in a homogenous group of adolescents with RPD, using MPFL reconstruction as the basic technique. The paper also analyses anatomical knee variations in the adolescent population with RPD and their influence on the therapeutic outcome.

\section{Materials And Methods}

\section{Patients}

Twenty-two patients reported to the follow-up examination after at least three years, including four patients who underwent bilateral surgery. In total, 26 knees were operated on. The group included 12 girls and ten boys, the mean age at the time of the surgery was 15.4 years (from 12 to 17 years, SD 1.4 years). The mean follow-up was 4.4 years (between three and seven years, SD 1.7 years).

\section{The study inclusion criteria:}

- patellar dislocation that occurred at least twice,

- completed research protocol,

- age under 18 at the time of surgery,

- graded at least IV in Tanner maturity scale

\section{Exclusion criteria:}

- Tanner maturity scale below IV,

- first time dislocation

- habitual dislocation,

- knee valgus angle more than 15 degrees

- osteochondral fracture 
- history of other knee injury or operation

\section{Clinical assessment}

The clinical assessment included a patellar apprehension test and j-sign. Knee valgus angle was also clinically assessed goniometrically. The subjects were asked to complete the Lysholm-Tegner Knee Scale and the Kujala Anterior Knee Pain Scale before surgery and after follow-up [21,22]. The Beighton joint laxity scale was utilised to assess joint laxity in the participants, with a score of $\geq 4$ being recognised as ligamentous laxity [23].

\section{Radiological assessment}

During both the preoperative and postoperative assessments, a lateral X-ray was performed in standing weight bearing position with full knee extension; axial X-rays were taken at 45 degrees of knee flexion with quadriceps isometric tension, according to Merchant. MRI was also performed to assess TT-TG distance, the Dejour classification of trochlear dysplasia and exclude osteochondral fracture, loose bodies or other ligamentous injuries. Based on the imaging results, the Caton-Deschamps Index (CDI), congruence angle (CA), patelofemoral angle (PFA) and Wiberg classification of the patella shape were assessed [24,25].

\section{Surgical technique}

In all cases, the gracilis tendon was harvested in the standard mini-invasive manner. In 11 cases, in which tibial tuberosity to trochlear grove (TT-TG) distance was more than $20 \mathrm{~mm}$ or congruence angle was greater than five degrees before surgery, osteotomy of the tibial tuberositas (TTO) was performed according to Fulkerson [8]. Lateral release was performed in 15 cases, where PFA was greater than 10 degrees. A guide pin was placed $1 \mathrm{~cm}$ distal to the adductor tubercle and $1 \mathrm{~cm}$ posterior to the femoral epicondyle. Patellar vertical canal $3.5 \mathrm{~mm}$-diameter in the proximal third was performed. The tendon was then looped through the patellar canal and passed above the synovial layer of the knee joint capsule to the femoral tunnel area. The double-bound tendon was then looped on a guide wire and the potential femoral insertion was checked to ensure that the graft remained isometric through a full range of motion. The guide wire positioning was adjusted until graft isometry was achieved. In the next step, a femoral canal $7 \mathrm{~mm}$ in diameter and $3-5 \mathrm{~cm}$ in length was drilled with an atraumatic drill. The graft was then inserted in the tunnel by pulling sutures on the lateral side of the femur, and was then fixed with a $7 \times 25 \mathrm{~mm}$ bioabsorbable screw at appropriate tension with the knee at 30 degrees of flexion. A knee brace and crutches were used in the postoperative period, with weight bearing being tolerable from third week post-op. The range of motion was set on the brace to 0-30 degrees after two weeks post-op and 0-60 degrees after four weeks. After six weeks, the brace was removed and a standard physiotherapy programme was initiated to restore full ROM and thigh muscle strength.

\section{Statistical analysis}

All continuous variables were tested with the Kolmogorov-Smirnov Test to confirm the normality of their distribution. Depending on the results, Wilcoxon's test or T-test were used to analyse the obtained data, 
together with Spearman's rho test and the Chi-Square Test for a four-field array with Yate's correction. Statistical significance was assumed for $p<0.05$.

\section{Registration and bioethics}

The research was approved by our Institutional Review Board (approval issue No 34/2019). The study was registered to ClinicalTrials.gov record No PMMHRI-BC0.34/2019. All the procedures were in accordance with the ethical standards of the responsible committee on human experimentation (institutional and national) and with the Helsinki Declaration of 1975, as revised in 2000 and 2008.

\section{Results}

Neither wound infection nor arthrofibrosis were observed in follow-up. Range of motion was restored in all 26 knees. In two cases, one incident of patellar redislocation was noted, with spontaneous reduction in follow-up period; both occurred as a result of knee torsion during sport activity. Neither case was reoperated. Their clinical and radiological parameters are listed in Table 1. In three cases, the apprehension sign was positive; in two of these, redislocation was noted. J-sign was evident in three cases, none of which demonstrated redislocation. In 11 patients, ligamentous laxity was indicated according to the Beighton score (mean 2.7 points, range 0-6, SD 1.69). Both the Lysholm-Tegner and Kujala Scale scores significantly improved after follow-up $(p<0.001)$, as recorded in Table 2.

The radiological analysis indicated that patellar height, measured as Caton-Deschamps index, did not change significantly $(\mathrm{p}=0.681$ ) (Table 2 ). The Dejour classification did not change after follow-up period in any knee, and 12 were described as class $A$, nine as $B$, three as $C$ and two as $D$. Patellar shape was classified as type I in three cases, type II in nine and type III in 11; in three knees, a "hunter's cup" type (Wiberg V) was described. The values of both PFA and CA significantly decreased after surgery $(p<0.001)$ (Table 2). An incorrect congruence angle (lateral subluxation, patellar shift) was present in 22 knees pre-op and ten post-op ( $p=0.002)$. Increased patellofemoral angle (patellar tilt) was present in 21 knees pre-op and seven post-op $(p<0.001)($ Table 3$)$.

A statistically significant correlation was demonstrated between PFA and both Lyscholm-Tegner and Kujala score (in both $p<0.001, r=-0.5$ ). A slight, but significant, correlation was found between CA and Kujala score $(p=0.008, r=-0.036)$; however, no such correlation was observed between CA and LyscholmTegner score $(p=0.051, r=-0.27)$.

When the cases were divided into two groups according to TTO, both groups demonstrated a significant decrease in CA from pre-op to post-op ( $p=0.003$ with TTO and $p=0.001$ without TTO).

\section{Discussion}


Our results indicate that the therapy proved effective. Lysholm and Kujala Scores improved significantly, and only two patients $(7.7 \%)$ suffered from redislocation, with no need to reoperate; both patients were performing highly-demanding activities. This recurrence rate is very similar to that reported in literature, which ranges from 1.2 to 13 percent $[10,12,14,16,26-30]$. Most previous works indicate improvement within the scope of functional scale. However, the populations included in these studies usually vary considerably with regard to age and implemented MPFL reconstruction methods, particularly concerning the use of TTO, and very few are based on groups with homogeneous age and maturation advancement. It is well known that the prior to adolescence, children demonstrate a much higher redislocation rate than adults. We believe that combining these groups does not provide a suitably homogeneous population to analyse the applied operating methods and preoperative qualification. In our cases, the treatment results were also confirmed by radiological indices: a significant improvement in two main indicators, namely CA and PFA, was observed in patients who did not have the TTO and lateral release performed. Interestingly, our findings indicate a significant correlation between the Kujala Score and the $\mathrm{CA}$, which confirms the substantial impact this index has on treating RPD.

In our study, we elaborated our own qualification to undergo lateral release; it was performed only in patients with PFA of more than 10 degrees, diagnosing a severe tilt. It is important to note that our results indicate a statistically significant correlation between PFA and both the Kujala and Lysholm scores; there is hence a need for a more detailed examination of the value of PFA, and it should be considered when planning surgery, especially in the case of unsatisfactory results or in patellofemoral pain cases. Malatray et al. report no indication for systemic lateral release in a population of 33 patients (18-45 years old) with MPFL reconstruction; no differences in International Knee Documentation Committee (IKDC) score or patellar tilt were found between those who underwent lateral release during MPFL and those who did not during a one - year follow-up [31].

Another parameter that has been analysed in literature is the influence of MPFL reconstruction on patellar height, expressed with the CDI index. Although patellar height in our cases was not corrected, the administered treatment proved successful, both with regard to the recurrence, and to the result of the subjective survey evaluation during the three-year follow-up. Nevertheless, a study by Luceri et al. found the patellar height decreasing in a group of 95 knees in mature patients after isolated MPFL reconstruction, mean age 25 years [32]. Similarly, Lykissas et al. report a significant decrease of patellar height indices after MPFL reconstruction in 38 patients, mean age 14.2 years, during a six month followup, as indicated by X-ray analysis [33].

The most controversial subject, and one that has been widely described in literature, is the mean of the femoral insertion positioning. In our practice, we use anatomical landmarks [18,19]. In the present study, none of the procedures used fluoroscopy guidance according to Schöttle; instead, graft isometry was employed, regardless of the femoral positioning. Despite this, McCarthy et al. propose that using nonanatomical points is associated with a worse result, and emphasise that graft tension is a more important factor [19]. However, an analysis of 27 cases of MPFL reconstruction including different femoral insertion placements by Larson et al. did not confirm worse outcomes in those with non-anatomical placement of 
femoral tunnel after a one-year follow-up [16]. Interestingly, in a study of 64 patients with a median age of 24 years old, Koenen et al. found that fluoroscopy enabled more accurate femoral tunnel positioning; however, this particular study did not include any comparison with the results obtained by other positioning methods [18].

Campos et al. emphasise that as far as trochlear dysplasia is concerned, the Schöttle's point is not suitable for a femoral tunnel; their study based on 40 cases indicates that it is better to use a more proximal point in this group of patients, and that taking this approach should improve accuracy in pre-op planning [34].

The qualification to TTO is another extremely interesting and very controversial issue. As mentioned above, some papers propose that distal realignment is unnecessary, as MPFL reconstruction alone can yield good results. A review of 27 knees by Pesenti et al. in children (mean age 13.8 years) treated with isolated MPFL reconstruction, regardless of anatomical osseous abnormalities, identified one recurrence (3.8\%), with a mean Kujala score of 95.5 points during 41 months of follow-up [12]. In another study of 211 isolated MPFL reconstructions with an mean age of 20.6 years, Sappey-Marinier et al. report a significant increase in the Kujala score over a 5.8-year follow-up; in addition, $4.7 \%$ recurrences required revision. No TTO was performed in any patient, even those with the increased TT-TG, patella alta and Jsign before surgery [14]. Similarly Mulliez et al. indicate no difference between patients who had TTO and those who did not, in a study of 129 knees with a minimum one-year follow-up [28]. These findings are confirmed by those of Erickson et al., regarding 90 patients with a mean age of 19 years who underwent RPD treatment: the findings indicate a good result over a two-year follow-up, regardless of anatomical factors such as the increased TT-TG, CDI or Dejour index [13].

In our present study, although we decided to strengthen the criteria concerning the TTO, we continued to take certain anatomical factors into consideration, i.e. TT-TG exceeding $20 \mathrm{~mm}$ and lateralisation of the patella in 45 degrees Merchant view expressed in CA of more than five degrees. Based on our past and present studies, we recommend this methodology in daily practice.

When compared with the available literature, the greatest limitation of our paper is the relatively small size of the study group. Our attempts to ensure a homogenous population unfortunately came at the expense of its size, and some subjects were inevitably lost during the follow-up. However, the study group we were able to create was of sufficient size to allow standardised statistical analysis. Additionally, our group size is equivalent or even larger than many used in previous studies [10-12,16,31]. Another disadvantage of our publication might be associated with the follow-up period, which should be longer to assess the real longterm results; nevertheless, a three-year follow-up seems to be longer than most used previously [10$13,16,31,33]$.

\section{Conclusions}

1. Surgical treatment causes a considerable improvement in the functional assessment of patients, as well as anatomical conditions within the patellofemoral joint. 
2. The population of patients suffering from recurrent patellar dislocation remains heterogeneous, as far as advancement of anatomical anomalies are concerned; hence, individual evaluation and preoperative qualification are needed.

3. There is no unequivocal opinion in the literature regarding optimal femoral MPFL fixation placement, as it is necessary to correct certain anatomical disorders; hence we intend to continue our research in RPD but with a longer follow-up in mind.

\section{Abbreviations}

RPD - recurrent patellar dislocation

CDI - Caton-Deschamps Index

CA - congruence angle

PFA - patellofemoral angle

MPFL - medial patellofemoral ligament

SD - standard deviation

TT-TG - tibial tuberosity to trochlear grove

TTO - tibial tuberositas osteotomy

IKDC - International Knee Documentation Committee

\section{Declarations}

\section{Ethics approval and consent to participate}

The study was approved by Polish Mother Memporial Hospital Review Board and registered on ClinicalTrials.gov (ID No PMMHRI-BC0.34/2019).

We confirm that informed consent was obtained from a parents and/or legal guardians as participants are under 16 years.

We confirm that all methods were carried out in accordance with relevant guidelines and regulations.

\section{Consent for publication}

Not applicable

\section{Availability of data and materials}


Along with ClinicalTrials registration conditions we are ready to share the raw data upon reasonable request. Responsible person Krzysztof Małecki e-mail: krzynormal@wp.pl.

Competing interests

None

Funding

Not applicable

Authors' contributions

K.M. - manuscript preparation, data collector, research director,

P.F. - manuscript edition, data interpretation

W.S.. - data collector

J.B.. - data collector

K.R.N. - research protocol design, supervisor

Acknowledgements

Not applicable

Funding: not applicable

Conflicts of interest/Competing interests: not applicable

Availability of data and material: The data that support the findings of this study are available from the corresponding author (KM) upon reasonable request.

Code availability: All data is avaibale in .xls or .ods file format

Authors' contributions:

KM; designed and directed the project, the main conceptual ideas and proof outline, worked out almost all of the technical details, and performed the numerical calculations, prepared manuscript

PF; contributed to the design and implementation of the research, contributed to the final manuscript

JB; developed the theoretical formalism, carried out the follow-up

WS; developed the theoretical formalism, carried out the follow-up

KRN; supervised the project, contributed to the final manuscript

All authors discussed the results and commented on the manuscript. 
Ethics approval: The research was approved by PMMHRI Institutional Review Board (approval issue No 34/2019)

Consent to participate: Informed consent according to IRB approval was given by participants.

Consent for publication: We agree, if and when the manuscript is accepted for publication, to automatic and free transfer of copyright to the Publisher allowing for the publication and distribution of the material submitted in all available forms and fields of exploitation. I confirm that all co-authors as well as the responsible authorities at our institution approved the manuscript and that it has not been submitted previously to another journal or published elsewhere.

\section{References}

1. Gruskay JA, Gomoll AH, Arendt EA, Dejour DH, Strickland SM (2020) Patellar Instability and Dislocation: Optimizing Surgical Treatment and How to Avoid Complications. Instr Course Lect. 2020;69:671-692.

2. Arendt EA, Dejour D, Farr J (2012) Patellofemoral instability. Sports Med Arthrosc Rev. Sep;20(3):127. doi: 10.1097/JSA.0b013e318262a0ce.

3. Previtali D, Milev SR, Pagliazzi G, Filardo G, Zaffagnini S, Candrian C (2020) Recurrent Patellar Dislocations Without Untreated Predisposing Factors: Medial Patellofemoral Ligament Reconstruction Versus Other Medial Soft-Tissue Surgical Techniques-A Meta-analysis. Arthroscopy. Jun;36(6):1725-1734. doi: 10.1016/j.arthro.2019.12.029.

4. Sillanpää P, Mattila VM, Visuri T, Mäenpää $H$, Pihlajamäki H (2008) Ligament reconstruction versus distal realignment for patellar dislocation. Clin Orthop Relat Res. Jun;466(6):1475-84. doi: 10.1007/s11999-008-0207-6.

5. Zaffagnini S, Dejour D, Grassi A, Bonanzinga T, Marcheggiani Muccioli GM, Colle F, Raggi F, Benzi A, Marcacci M (2013) Patellofemoral anatomy and biomechanics: current concepts. Joints. Oct 24;1(2):15-20.

6. Zaffagnini S, Previtali D, Tamborini S, Pagliazzi G, Filardo G, Candrian C (2019) Recurrent patellar dislocations: trochleoplasty improves the results of medial patellofemoral ligament surgery only in severe trochlear dysplasia. Knee Surg Sports Traumatol Arthrosc. Nov;27(11):3599-3613. doi: 10.1007/s00167-019-05469-4.

7. Geierlehner A, Liebensteiner M, Schöttle P, Dirisamer F (2020) Prevailing disagreement in the treatment of complex patellar instability cases: an online expert survey of the AGA KneePatellofemoral Committee. Knee Surg Sports Traumatol Arthrosc. Aug;28(8):2697-2705. doi: 10.1007/s00167-020-05936-3.

8. Dejour D, Le Coultre B (2018) Osteotomies in Patello-Femoral Instabilities. Sports Med Arthrosc Rev. Mar;26(1):8-15. doi: 10.1097/JSA.0000000000000183.

9. Vellios EE, Trivellas M, Arshi A, Beck JJ (2020) Recurrent Patellofemoral Instability in the Pediatric Patient: Management and Pitfalls. Curr Rev Musculoskelet Med. Feb;13(1):58-68. doi: 
10.1007/s12178-020-09607-1.

10. Spang RC, Tepolt FA, Paschos NK, Redler LH, Davis EA, Kocher MS (2019) Combined Reconstruction of the Medial Patellofemoral Ligament (MPFL) and Medial Quadriceps Tendon-Femoral Ligament (MQTFL) for Patellar Instability in Children and Adolescents: Surgical Technique and Outcomes. J Pediatr Orthop. Jan;39(1):e54-e61. doi: 10.1097/BP0.0000000000001259.

11. Nelitz M, Dreyhaupt J, Williams SRM (2018) Anatomic reconstruction of the medial patellofemoral ligament in children and adolescents using a pedicled quadriceps tendon graft shows favourable results at a minimum of 2-year follow-up. Knee Surg Sports Traumatol Arthrosc. Apr;26(4):1210-1215. doi: 10.1007/s00167-017-4597-4.

12. Pesenti S, Ollivier M, Escudier JC, Cermolacce M, Baud A, Launay F, Jouve JL (2018) Choufani E. Medial patellofemoral ligament reconstruction in children: do osseous abnormalities matter? Int Orthop. Jun;42(6):1357-1362. doi: 10.1007/s00264-017-3750-5.

13. Erickson BJ, Nguyen J, Gasik K, Gruber S, Brady J, Shubin Stein BE (2019) Isolated Medial Patellofemoral Ligament Reconstruction for Patellar Instability Regardless of Tibial TubercleTrochlear Groove Distance and Patellar Height: Outcomes at 1 and 2 Years. Am J Sports Med. May;47(6):1331-1337. Doi: 10.1177/0363546519835800.

14. Sappey-Marinier E, Sonnery-Cottet B, O'Loughlin P, Ouanezar H, Reina Fernandes L, Kouevidjin B, Thaunat M (2019) Clinical Outcomes and Predictive Factors for Failure With Isolated MPFL Reconstruction for Recurrent Patellar Instability: A Series of 211 Reconstructions With a Minimum Follow-up of 3 Years. Am J Sports Med. May;47(6):1323-1330. doi: 10.1177/0363546519838405.

15. Sillanpää PJ, Mattila VM, Visuri T, Mäenpää H, Pihlajamäki H (2011) Patellofemoral osteoarthritis in patients with operative treatment for patellar dislocation: a magnetic resonance-based analysis. Knee Surg Sports Traumatol Arthrosc. Feb;19(2):230-5. doi: 10.1007/s00167-010-1285-z.

16. Larson E, Edwards A, Albright J (2014) Functional outcomes of MPFL reconstruction vs. graft tissue placement. lowa Orthop J. 2014;34:38-43.

17. Carnesecchi O, Neri T, Di lorio A, Farizon F, Philippot R (2015) Results of anatomic gracilis MPFL reconstruction with precise tensioning. Knee. Dec;22(6):580-4. doi: 10.1016/j.knee.2015.01.006.

18. Koenen P, Shafizadeh S, Pfeiffer TR, Wafaisade A, Bouillon B, Kanakamedala AC, Jaecker V (2018) Intraoperative fluoroscopy during MPFL reconstruction improves the accuracy of the femoral tunnel position. Knee Surg Sports Traumatol Arthrosc. Dec;26(12):3547-3552. doi: 10.1007/s00167-0184983-6.

19. McCarthy M, Ridley TJ, Bollier M, Wolf B, Albright J, Amendola A (2013) Femoral tunnel placement in medial patellofemoral ligament reconstruction. Iowa Orthop J. 2013;33:58-63.

20. Nelitz M, Dreyhaupt J, Reichel H, Woelfle J, Lippacher S (2013) Anatomic reconstruction of the medial patellofemoral ligament in children and adolescents with open growth plates: surgical technique and clinical outcome. Am J Sports Med. Jan;41(1):58-63. doi: 10.1177/0363546512463683.

21. Kujala UM, Jaakkola LH, Koskinen SK, Taimela S, Hurme M, Nelimarkka O (1993) Scoring of patellofemoral disorders. Arthroscopy. 1993;9(2):159-63. doi: 10.1016/s0749-8063(05)80366-4. 
22. Tegner Y, Lysholm J (1985) Rating systems in the evaluation of knee ligament injuries. Clin Orthop Relat Res. Sep;(198):43-9.

23. Beighton P, Solomon L, Soskolne CL (1973) Articular mobility in an African population. Ann Rheum Dis. Sep;32(5):413-8. doi: 10.1136/ard.32.5.413.

24. Merchant AC, Mercer RL, Jacobsen RH, Cool CR (1974) Roentgenographic analysis of patellofemoral congruence. J Bone Joint Surg Am. Oct;56(7):1391-6.

25. Dejour H, Walch G, Nove-Josserand L, Guier C (1994) Factors of patellar instability: an anatomic radiographic study. Knee Surg Sports Traumatol Arthrosc. 1994;2(1):19-26. doi:

10.1007/BF01552649.

26. Enderlein D, Nielsen T, Christiansen SE, Faun $\varnothing$ P, Lind M (2014) Clinical outcome after reconstruction of the medial patellofemoral ligament in patients with recurrent patella instability. Knee Surg Sports Traumatol Arthrosc. Oct;22(10):2458-64. doi: 10.1007/s00167-014-3164-5.

27. Carnesecchi O, Neri T, Di lorio A, Farizon F, Philippot R (2015) Results of anatomic gracilis MPFL reconstruction with precise tensioning. Knee. Dec;22(6):580-4. doi: 10.1016/j.knee.2015.01.006.

28. Mulliez A, Lambrecht D, Verbruggen D, Van Der Straeten C, Verdonk P, Victor J (2017) Clinical outcome in MPFL reconstruction with and without tuberositas transposition. Knee Surg Sports Traumatol Arthrosc. Sep;25(9):2708-2714. doi: 10.1007/s00167-015-3654-0.

29. Puzzitiello RN, Waterman B, Agarwalla A, Zuke W, Cole BJ, Verma NN, Yanke AB, Forsythe B (2019) Primary Medial Patellofemoral Ligament Repair Versus Reconstruction: Rates and Risk Factors for Instability Recurrence in a Young, Active Patient Population. Arthroscopy. Oct;35(10):2909-2915. doi: 10.1016/j.arthro.2019.05.007.

30. Malecki K, Fabis J, Flont P, Lipczyk Z, Niedzielski K (2016) Preliminary results of two surgical techniques in the treatment of recurrent patellar dislocation : Medial patellofemoral ligament reconstruction versus combined technique of vastus medialis advancement, capsular plasty and Roux-Goldthwait procedure in treatment of recurrent patellar dislocation. Int Orthop. Sep;40(9):186974. doi: 10.1007/s00264-016-3119-1.

31. Malatray M, Magnussen R, Lustig S, Servien E (2019) Lateral retinacular release is not recommended in association to MPFL reconstruction in recurrent patellar dislocation. Knee Surg Sports Traumatol Arthrosc. Aug;27(8):2659-2664. doi: 10.1007/s00167-018-5294-7.

32. Luceri F, Roger J, Randelli PS, Lustig S, Servien E (2020) How Does Isolated Medial Patellofemoral Ligament Reconstruction Influence Patellar Height? Am J Sports Med. Mar;48(4):895-900. Doi: $10.1177 / 0363546520902132$.

33. Lykissas MG, Li T, Eismann EA, Parikh SN (2014) Does medial patellofemoral ligament reconstruction decrease patellar height? A preliminary report. J Pediatr Orthop. Jan;34(1):78-85. doi: 10.1097/BPO.0b013e3182a12102.

34. Campos T, Soogumbur A, McNamara IR, Donell ST (2018) The trochlear isometric point is different in patients with recurrent patellar instability compared to controls: a radiographical study. Knee Surg Sports Traumatol Arthrosc. Sep;26(9):2797-2803. doi: 10.1007/s00167-017-4740-2. 


\section{Tables}

Tab. 1 Clinical and radiological parameters in two cases of incidence of patellar redislocation.

\begin{tabular}{|c|c|c|c|c|c|c|c|c|}
\hline & $\begin{array}{l}\text { No of } \\
\text { recurences }\end{array}$ & $\begin{array}{l}\text { Kujala } \\
\text { Score } \\
\text { pre/post } \\
\text { op } \\
\text { (points) }\end{array}$ & $\begin{array}{l}\text { Age at } \\
\text { surgery/ } \\
\text { Follow - } \\
\text { up } \\
\text { (years) }\end{array}$ & $\begin{array}{l}\text { Beighton } \\
\text { score } \\
\text { (points) }\end{array}$ & CDI & $\begin{array}{l}\text { PFA } \\
\text { (degrees) }\end{array}$ & $\begin{array}{l}\text { CA } \\
\text { (degrees) }\end{array}$ & $\begin{array}{l}\text { Dejour } \\
\text { clas. }\end{array}$ \\
\hline $\begin{array}{l}\text { Pat } \\
\text { No } \\
1\end{array}$ & 1 & $56 / 78$ & $14 / 6$ & 4 & $1.29 / 1.22$ & $6 /-10$ & $32 / 14$ & B \\
\hline $\begin{array}{l}\text { Pat } \\
\text { No } \\
2\end{array}$ & 1 & $56 / 87$ & $17 / 7$ & 5 & $1.3 / 1.32$ & $30 / 5$ & $30 / 10$ & C \\
\hline
\end{tabular}

Tab. 2 Analysis of Lysholm-Tegner and Kujala Scale scores, and congruence angle (CA), patellofemoral angle (PFA), Caton-Deschoumps index (CDI) values pre-op and post-op (X-mean, SD - standard deviation).

\begin{tabular}{|c|c|c|c|c|c|}
\hline & & Pre-op & Post-op & & \\
\hline \multirow[t]{2}{*}{ Lysholm-Tegner Scale } & $\mathrm{x}$ & 61.6 & 90.1 & $t=9.078$ & $p<0.001$ \\
\hline & SD & 18.0 & 10.5 & & \\
\hline \multirow[t]{2}{*}{ Kujala Scale } & $x$ & 62.2 & 87.5 & $t=8.141$ & $p<0.001$ \\
\hline & SD & 16.5 & 12.6 & & \\
\hline \multirow[t]{2}{*}{ Congruence angle (CA) } & $\mathrm{x}$ & 26.8 & 4.7 & $t=-8.721$ & $p<0.001$ \\
\hline & SD & 17.2 & 14.1 & & \\
\hline \multirow[t]{2}{*}{ Patellofemoral angle (PFA) } & $\mathrm{x}$ & 9.8 & -3.4 & $t=-8.850$ & $p<0.001$ \\
\hline & SD & 10.2 & 6.6 & & \\
\hline \multirow[t]{2}{*}{ Caton-Deschoumps index (CDI) } & $x$ & 1.20 & 1.16 & $z=-0.408$ & $p=0.681$ \\
\hline & SD & 0.30 & 0.28 & & \\
\hline
\end{tabular}

Tab. 3 Analysis of categorical values of the congruence angle (CA), patellofemoral angle (PFA) pre-op and post-op. 


\begin{tabular}{|llllllll|}
\hline & Pre-op & \multicolumn{5}{c|}{ Post-op } & \\
\cline { 2 - 6 } & incorrect & correct & incorrect & correct & & \\
Congruence angle (CA) & 22 & 4 & 10 & 16 & Chi $^{2}=9.831$ & $\mathrm{p}=0.002$ \\
\hline Patellofemoral angle (PFA) & 21 & 5 & 7 & 19 & Chi $^{2}=13.077$ & $\mathrm{p}<0.001$ \\
\hline
\end{tabular}

\section{Figures}
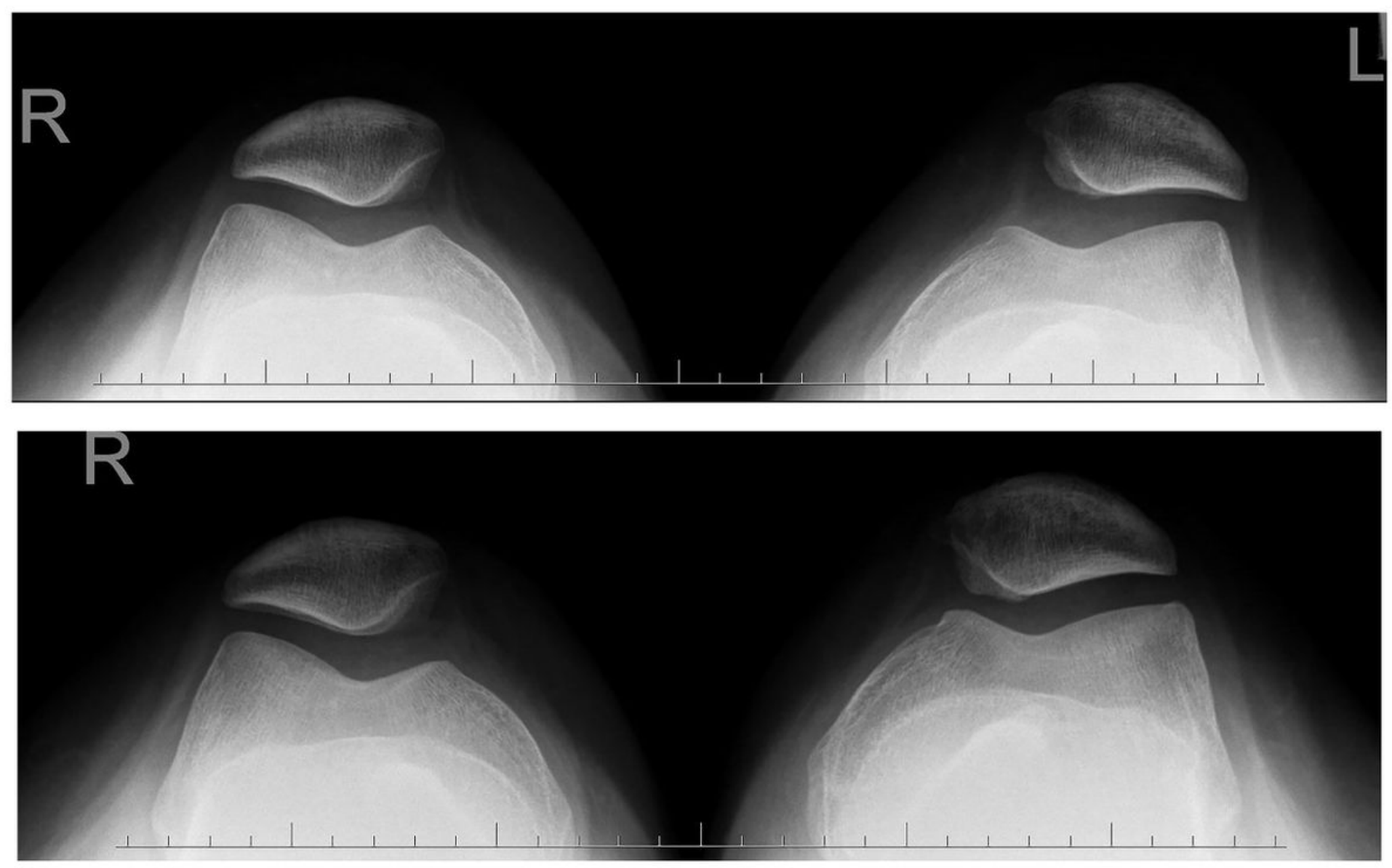

\section{Figure 1}

a Pre-operative axial view according to Merchant, left patella in shift and slight tilt. b Same patient postoperative, left patella in normal position. 